\title{
Hidroquímica da Amazônia Central III. Química da água de lavagem da floresta no ecossistema Campina Amazônica (Stemflow)
}

\author{
Antonio dos Santos ("), Maria de Nazaré Góes Ribeiro ("), Jorge Salomão B. Ribeiro (") e \\ Sérgio Roberto B. Bringel (")
}

\begin{abstract}
Resumo
No período de junho de 1974 a maio de 1975 , foi estudada, através de análises quimicas, a água de lavajem da floresta em três agrupamentos florísticos na Reserva Biológica de Campina. Esta abordagem procurou quantificar a entrada de ions e compostos orgâ. nicos nutritivos usados por macro e micropopulaçōes como fonte de energia e alimento, lixiviados através das precipitações do dossel da floresta. Os resultados das determinações químicas e físico-quimicas (médias mensais) mostraram que nos três agrupamentos existem pequenas diferenças individuais nas quantidades carreadas de P-total $\mathrm{N}-\mathrm{NO}_{-3} \mathrm{e} \mathrm{Ca}^{2+}$, enquanto que $\mathrm{N}-\mathrm{NH}^{2}{ }_{4}$, N-Orgânico, $\mathrm{N}$-total e $\mathrm{Mg}^{2+}$ apresentaram diferenças quantitativas apreciáveis. Entretanto as maiores quantidades lixiviadas foram de material orgânico. Os compostos nitrogenados mostraram ser mais facilmente carreados, seguidos em ordem decrescente do cálcio, magnésio e fósforo total em todo o sistema, exceção feita à campina onde a concentração de magnésio superou a do cálcio. As variaçōes sazonais observadas com a liberação e transporte de nutrientes do dossel da floresta para o solo, estão intimamente ligadas à duração, à intensidade e à distribuição da precipitação pluvial, na área estudada.
\end{abstract}

\section{INTRODUÇÃO}

Nos anos recentes, pesquisas têm sido realizadas na floresta pluvial equatorial, na Amazônia Central, no sentido de quantificar o ciclo de nutrientes minerais em suas formações neste ecossistema (Klinge \& Rodrigues, 1968 e 1974; Stark, 1971a, b; Brinkmann \& Santos, 1970, 1971, 1972 e 1973; Stark \& Holley, 1975; Santos \& Ribeiro, 1975; Klinge, 1976a, b, e 1977; Ribeiro et al., 1978).

O grande objetivo destas abordagens tem sido a procura de soluções racionais para um melhor aproveitamento dos solos pobres em nutrientes da formação terciária Série das Barreiras.
Alguns destes estudos têm procurado quantificar os elementos biologicamente importantes nos vários compartimentos (serrapilheiras, gotas, água da floresta, precipitação direta, água do solo, etc.), dos ecossistemas florestais. Parte deles tem caracterizado especificamente o conteúdo de um ou mais elementos minerais em cada compartimento e sua importância no ciclo de nutrientes, outros mostram dados isolados sem estar relacionados com as variações sazonais e/ou outros parâmetros ambientais.

Entretanto, apesar destas abordagens, ainda são escassos os dados a cerca da recic!agem de elementos nutritivos na floresta pluvial equatorial, quando comparadas às pesquisas e estudos desenvolvidos em outras regiôes tropicais e temperadas onde se destacam os trabalhos de Mecklenburg \& Tuckey (1964), Tuckey, Mecklenburg \& Morgan (1965, Carlisle et al. (1966), Borman \& Likens (1967), Attwill (1966), Thomas (1969), Wittwer \& Teubner (1969), Gosz et al. (1972) e Borman \& Likens (1973).

A partir destes estudos, tentamos aplicar no ecossistema Campina Amazônica uma abordagem idêntica com a finalidade de poder quantificar e avaliar as variações sazonais neste sistema, contribuindo assim para uma melhor visualização e caracterização ecológica do mesmo.

Sabe-se que os nutrientes são transportados até o solo principalmente pela queda de detritos (folhas, galhos, etc.) da serrapilheira. onde, após sua decomposição por microorganismos, eles são incorporados pelo sistema radicular dos vegetais superiores e/ou são utilizados por micropopulações como fonte de alimento e energia para seus processos vitais,

(") - Instituto Nacional de Pesquisas da Amazônia, Manaus. 
podendo ainda serem levados para fora do sis. tema como mostrado por: Santos et al. (1978), Klinge \& Rodrigues (1968), Kira \& Shidei (1967), Klinge \& Rodrigues (1971) e Klinge (1976)

Todavia, na Amazônia Central, uma outra fração de nutrientes bastante significativa é transferida para o solo, através da água de lavagem da floresta. Esta entrada de nutrientes torna-se mais importante se considerarmos o potencial de precipitação pluviométrica na Bacia Amazônica, estimada em cerca de $14.4 \times 10^{12} \mathrm{~m}^{3}$. ano-1 (Vila Nova et al., 1976).

Em contraste com a incorporação pela serrapilheira que necessita de um potente trabalho de degradação por parte de microorganismos e, conseqüentemente, uma enorme perda de energia, os nutrientes levados até ao solo pela água de lavagem da floresta são diretamente utilizados pela vegetação sem a interferência dos processos por que passa a massa vegetal caída.

No sistema estudado, esta lavagem das folhas, galhos e troncos promove uma entrada direta de nutrientes assimiláveis pela vegetação e micropopulação sendo talvez, o mais im- portante compartimento, visto que o solo are. noso pobre em bases trocáveis e outros compostos minerais mantém uma flora exuberan. te e rica em diversidade de espécies.

\section{MATERIAL E MÉTODOS}

A área de estudos é uma formação arenosa entre os km. 60 e 62 da rodovia BR-174 (trecho Manaus-Caracaraí) estando situado dentro do Distrito Agropecuário da SUFRAMA. Sua localização geográfica é mostrada na figura 1.

O sistema tem sido utilizado nos últimos anos como base para as pesquisas desenvolvidas pelo INPA nas áreas de: botânica - Anderson et al. (1975), Braga \& Braga (1975), Lisboa (1975) e outros; climatologia - Ribeiro \& Santos (1975); hidroquímica - Santos \& Ribeiro (1975), Ribeiro et al. (1978) e Santos et al. (não publicado).

O material para estudos químicos e físico-químico constou de amostras de água de lavagem da floresta, sendo que as mesmas foram colhidas em intervalos semanais dirarite

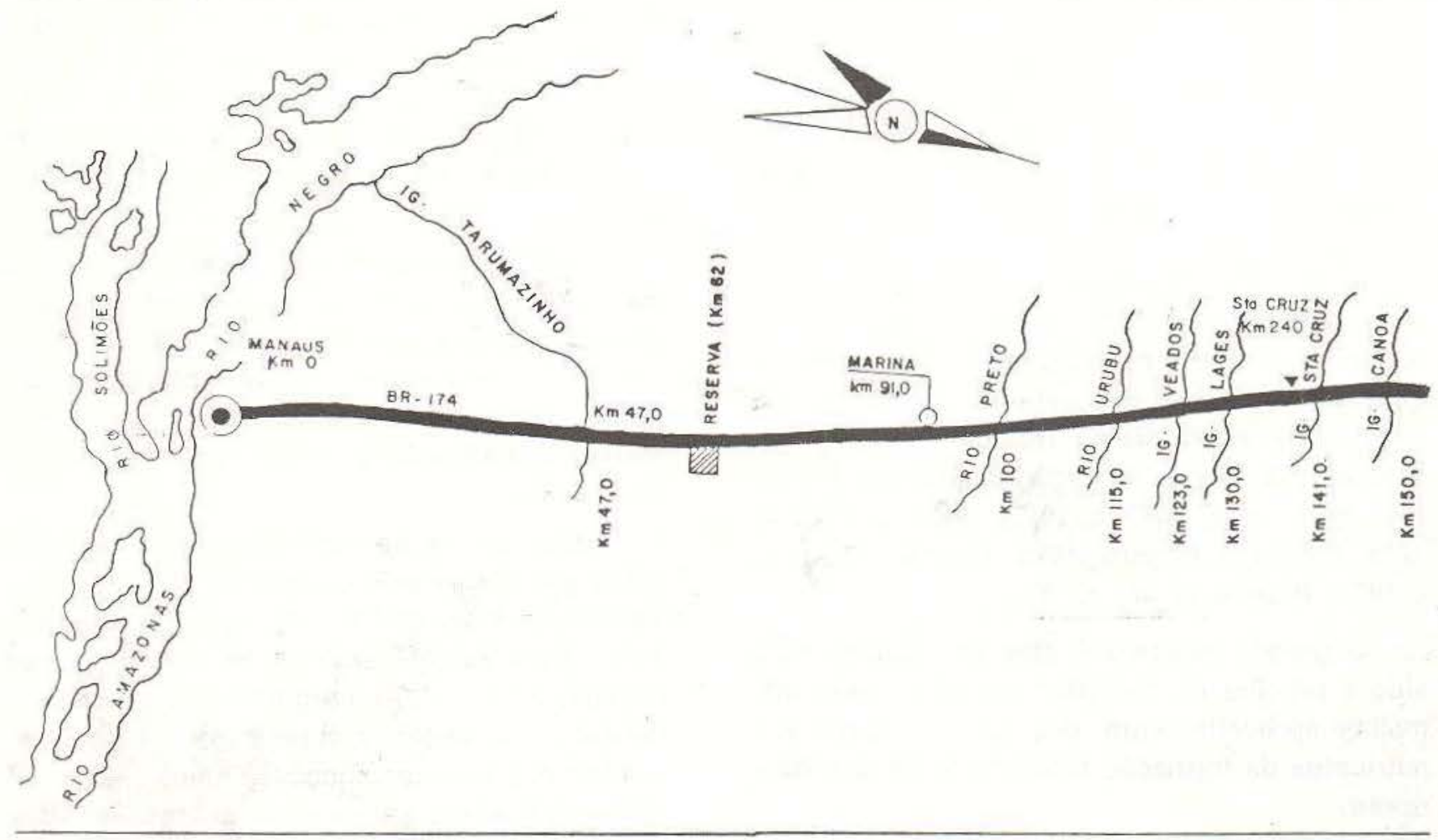

Fig. 1 - Area de estudos - Reserva Biológica de Campina (Rod. BR-174) trecho Manaus-Caracaraí. 
o período de um ano (junho de 1974 a maio de 1975), cobrindo um período seco e um chuvoso.

Para a coleta das amostras foram escoIhidas ao acaso quatro árvores na mata, quatro na campina e igual número na campinarana. Em seus troncos foram instalados coletores, a fim de recolher a água de lavagem que escorre pela superficie dos mesmos e cujo detalhe é mostrado esquematicamente na figura 2.

A metodologia analítica aplicada nesta abordagem está descrita com detalhes em Brinkmann \& Santos (1970, 1971, 1972, 1973); Santos \& Ribeiro (1975), Schmidt (1972) e Ribeiro $e t$ al. (1978), năo sendo portanto apresentada neste trabalho.

\section{Resultados E Discussão}

$\mathrm{pH}$ - Conforme mostrado por vários pesquisadores (Tabela 1), os valores de $\mathrm{pH}$ das águas naturais e dos solos das formações terciárias da Amazônica Central, variam de uma

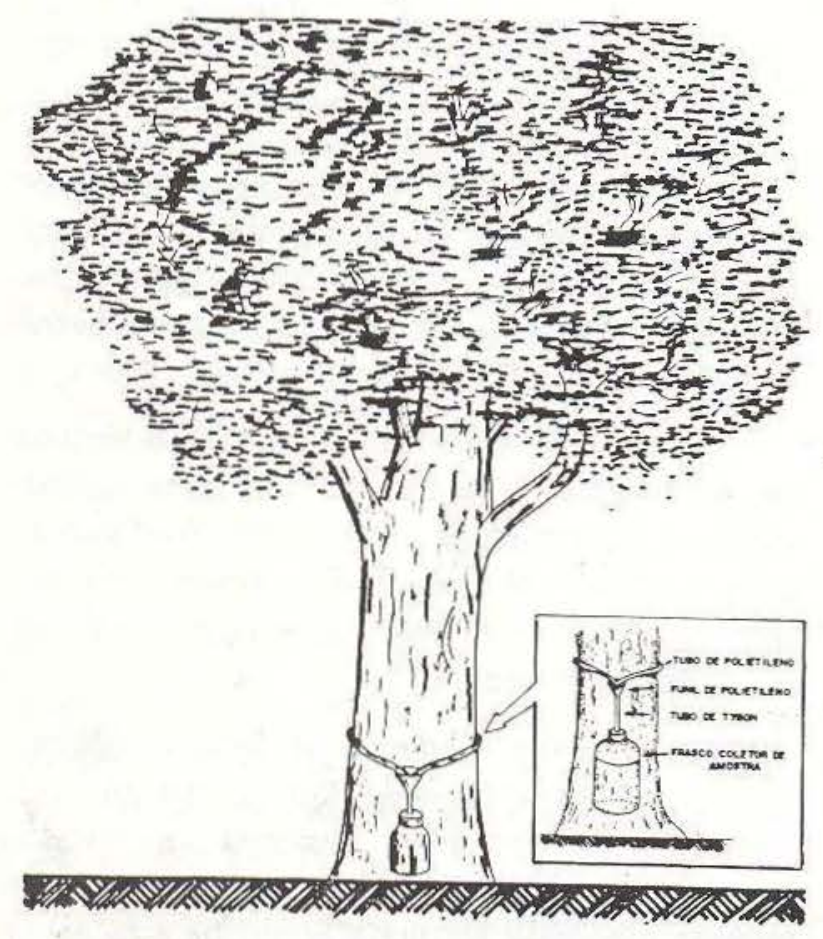

Fig. 2 - Esquema do processo de coletas de amostras. faixa de 4-6, mostrando que a capacidade de tamponamento dos solos e águas é extremamente baixo. Isto fica cada vez mais evidenciado por sua baixa, CTC IPEAN (1969) e IPEAAOC (1971). Vieira (1975) confirma os resultados de nossa observação, sugerindo que os valores de CTC encontrados para os solos podem ser claramente visualizados pelos valores de $\mathrm{pH}$ encontrados nas águas naturais, visto que, em nenhum lugar do mundo, estes dois compartimentos (solo e água) estão tão intimamente ligados como na Amazônia Central.

Nos ecossistemas aquáticos (rios, igarapés, lagos, etc.) da região terciária, os valores de $\mathrm{pH}$ medidos por Sioli (1956), Anon (1972b), Brinkmann \& Santos (1971) e Reiss (1976) sugerem que o conteúdo das bases trocáveis (cálcio, magnésio, potássio) nas águas de drenagem, é afetado sob duas hipóteses: a) estas bases estão circulando dentro do próprio ecossistema florestal; b) estas bases estão sendo removidas por organismos ou estão complexadas pelas substâncias húmicas presentes não tomando mais parte na circulação biogênica dos elementos nutritivos.

Como mostrado na figura 3 as variações sazonais do $\mathrm{pH}$ (médias mensais) em três formações florísticas diferentes, sugerem que os metabólitos excretados por microorganismos e pela própria vegetação, tornam a água de lavagem da floresta bem tamponada. Entretanto, os valores do $\mathrm{pH}$ dependem da composição florística e da espécie vegetal, fornecendo assim capacidade de suporte para o desenvolvimento da flora e fauna eventualmente presentes nos caules destas árvores.

Estas variaçōes do valor do $\mathrm{pH}$ nas diferentes espécies vegetais dentro do ecossistema, pressupõe a hipótese de que, existem variações consideráveis das micro populaçōes no pálio florestal, as quais promovem um contínuo trabalho de desdobramento das substâncias excretadas pela vegetação e/ou introduzidas por outros organismos.

Por outro lado, a comparação entre os valores de $\mathrm{pH}$ encontrados nas águas dos caules entre 5 e 7 e água do lençol freático entre 3 e 4 (Santos não publicado), indica que as bases

Hidroquímica. . 


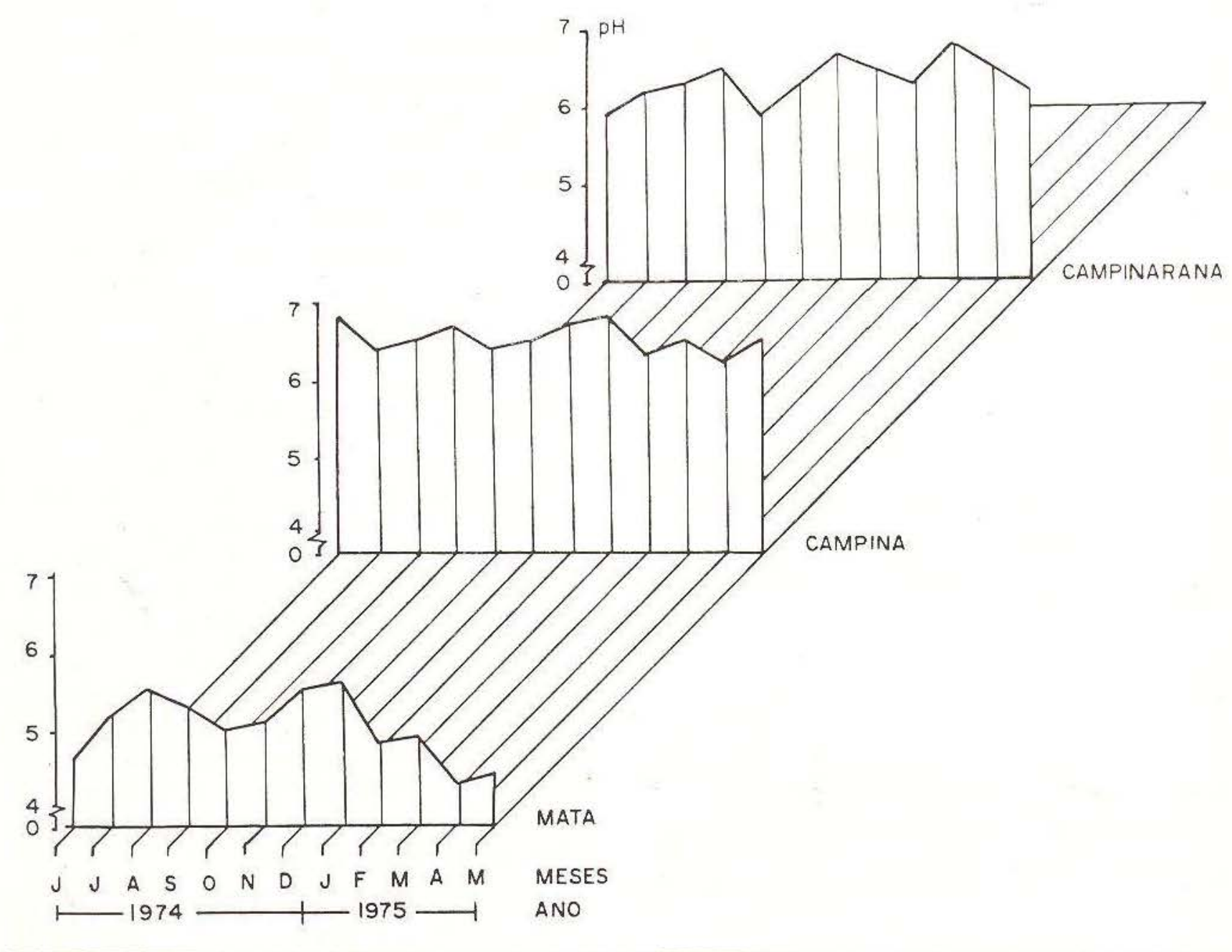

Fig. 3 - Variação sazonal de pH (médias mensais).

responsáveis pelo poder tampão destes solos devem ser reabsorvidas (uptake) rapidamente através de um mecanismo fisiológico ainda desconhecido, não chegando assim a serem carreadas para fora do sistema.

Os valores de $\mathrm{pH}$ na campina e na campinarana são só levemente influenciados pelas precipitações, enquanto que na mata esta variação é bem mais acentuada, uma pequena variação média entre a estação seca (junho a novembro) e estação chuvosa (dezembro a maio) de 0.2 unidades mostra que o valor $\mathrm{pH}$ independe da intensidade da precipitação dentro do ecossistema.

MATERIAL ORGÂNICO - A figura 4 mostra as variações sazonais do material orgânico oxidável, onde são incluídas principalmente as substâncias húmicas formadas a partir da ati- vidade das macro e micropopulações, acentuando a influência direta destas nos processos de transformação e desdobramento da matéria orgânica morta ou viva, dentro dos ecossistemas florestais.

Os valores medidos, no sistema estuda. do, evidenciam a existência de uma grande variação qualitativa e quantitativa nas populações microbianas, as quais utilizam este material como fonte de energia e nutrientes dentro do pálio florestal.

Aguas com elevadas concentrações de material orgânico dissolvido (100 a $450 \mathrm{mg}$. I - ') $^{-}$ foram encontradas entre as águas dos troncos (stemflow) na flaresta pluvial equatorial e em regatos drenando terrenos arenosos nas áreas desmatadas perto de Manaus Brinkmann \& Santos (1970). Estes valores elevados nas águas 


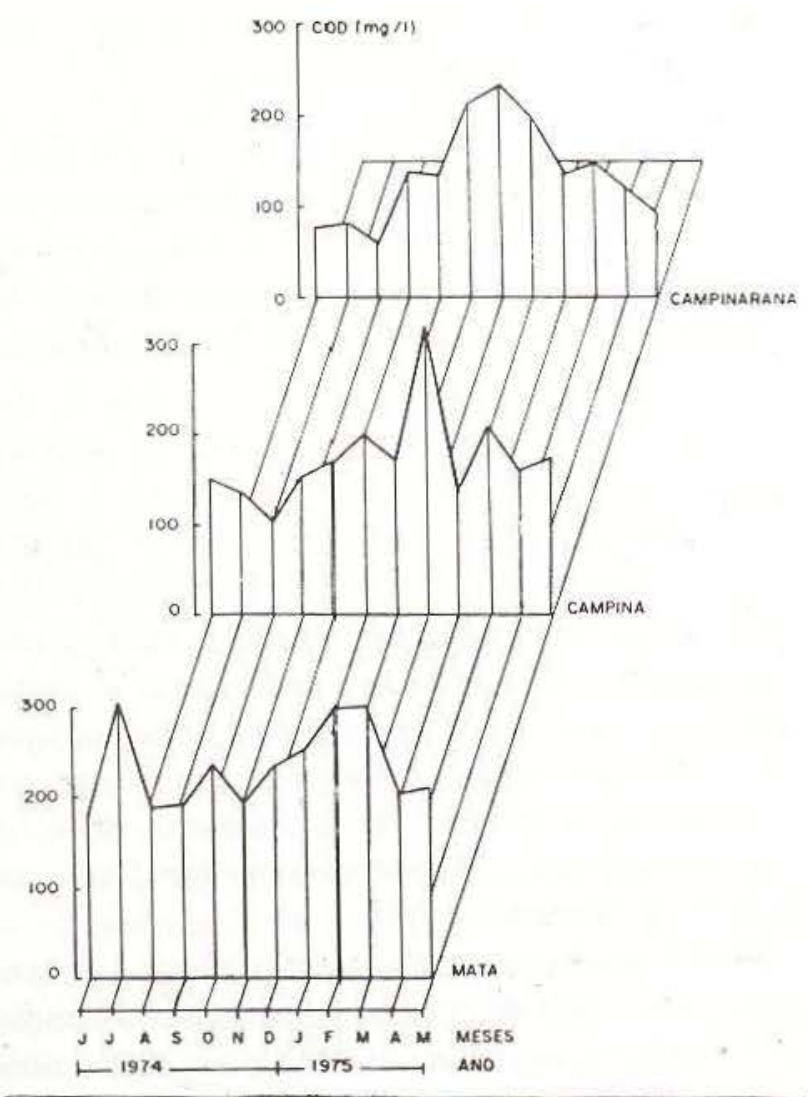

Fig. 4 - Variação sazonal de material orgânico oxidável, médias mensais.

dos troncos refletem o intenso trabalho de metabolização do material orgânico, cujos resíduos em forma de substâncias em via de humificação ou humificadas são acumuladas nos tufos de raizes das orquídeas e bromeliáceas principalmente, sendo, a seguir, transportadas para o solo pela água de lavagem da floresta, sujeita a uma precipitação média anual superior a $2.000 \mathrm{~mm}$ Ribeiro (1976).

O estudo comparativo, dentro do sistema, mostra que a concentração de material orgânico oxidável em Glycoxylon inophyllum (casca doce) campinarana é afetada durante o final da estação chuvosa e início da estação seca, provavelmente por força da remoção das cascas, por desprendimento destas do caule. Todavia, no meio da estação seca até à metade da estação chuvosa, este mecanismo de remoção deve estar reduzido ao mínimo.

Nas árvores de G. inophyllum, onde foram instalados os coletores, não foi evidenciada a presença de orquídeas, bromélias ou outras quaisquer epifitas, fato este também reportado por Braga \& Braga (1975) e Lisboa (1976). Isto vem sugerir que o alto conteúdo de material orgânico oxidável nas outras formaçōes é função da associação destas espécies com as árvores suportes, ainda segundo Lisboa (1976) o caule de $G$. inophyllum excreta substâncias tóxicas as quais impedem o desenvolvimento desta associação.

Nas árvores de Aldina heterophyla (macucu) na campina e aquelas da mata (não identificadas) onde os coletores foram instalados, pode ser observado, a partir dos dados apresentados na figura 4, que a variação sazonal do material orgânico oxidável não mostra diferenças significativas entre as estações seca e chuvosa, sugerindo assim que orquídeas, bromélias e outras aglomerações de epifitas, bem como as micro populaçöes acompanhantes destas espécies, têm relevante papel no desdobramento do material orgânico acumulado em seus troncos, assim como no trabalho de mineralização deste material, utilizando os produtos de degradação como fonte de alimento e energia.

Estes valores máximos de material oxidável para água dos troncos no sistema estudado representam em média de 3 a 4 vezes as concentrações no rio Negro, de 8 a 10 as concentraçōes para as precipitações pluviométricas (ANON, 1972a) e de 4 a 7 vezes os valores encontrados para os igarapés de água preta da floresta equatorial perto de Manaus, Brinkmann \& Santos (1970) e Schmidt (1972).

NITROGÊNIO AMONIACAL - A figura 5 mostra a concentração de $\mathrm{N}-\mathrm{NH}+_{4}$ nas várias formações vegetais dentro do sistema. Os valores maiores encontrados durante a estação seca, mostram que este composto é diretamente influenciado pela precipitação.

Existem variações na quantidade desta forma de nitrogênio entre as espécies tomadas na amostragem. Nota-se que as amostras coletadas nos troncos de $G$. inophyllum, apresentam valores médios mensais mais baixos do que as coletadas na mata e ambas menores que as coletadas na campina nos troncos de $A$. heterophylla. Estas variações, no intra- 


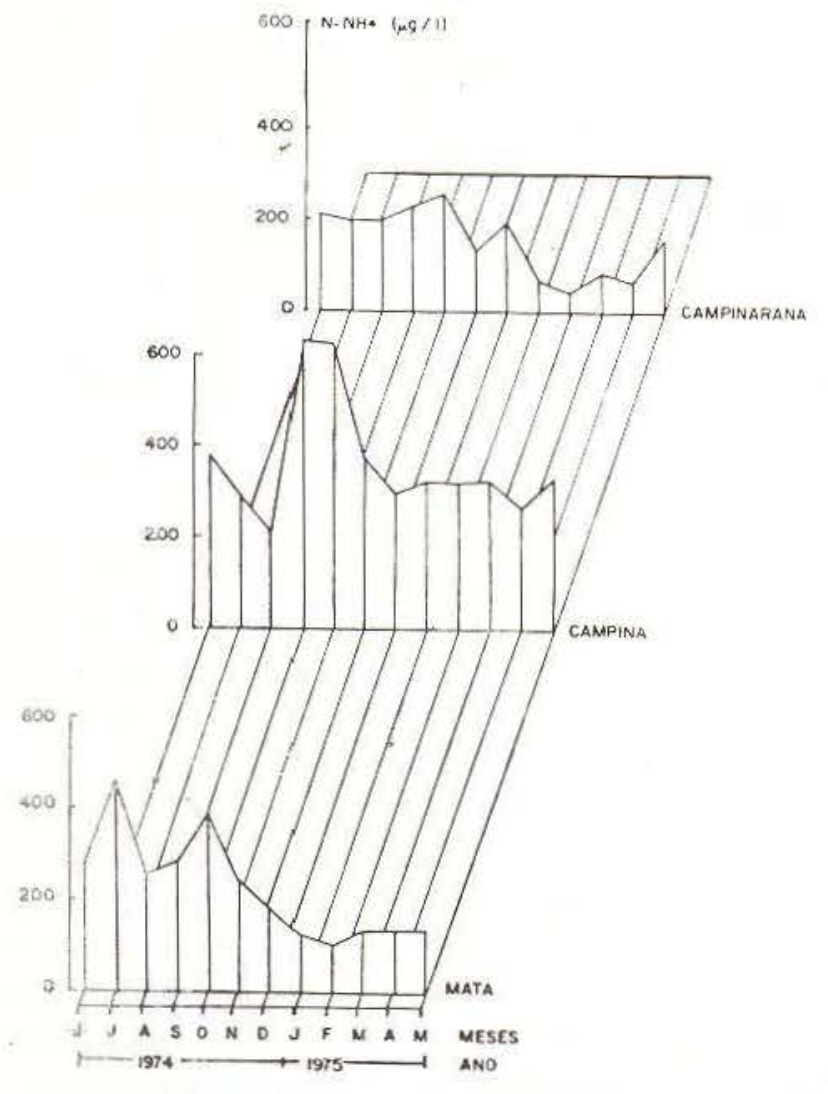

Fig. 5 - Variaçăo sazonal de nitrogênio amoniaca! \{ug/1) médias mensais.

sistema, podem ser atribuídas ao acúmulo de material orgânico depositado nos tufos formados pelas epifitas principalmente em $A$, heterophylla, permitindo assim um trabalho mais constante da microfauna aí instalada. Esta possibilidade torna-se mais evidente pelos valores quase constantes na campina, com picos em outubro e novembro, causados pela lavagem do pálio florestal durante as primeiras precipitações que precedem o início do período chuvoso.

As maiores concentrações de nitrogênio amoniacal, no período seco (junho a novembro), são explicadas pelo maior tempo de residência das excreções metabólicas, durante este tempo, fazendo com que precipitações isoladas e de menor intensidade, promovam uma maior dissolução do complexo, aumentando assim sua concentração.

Esta entrada de nitrogênio amoniacal, através da água que escorre pelos troncos, é uma importante fonte de suprimento deste nu- triente para os vegetais superiores nos ecossistemas florestais.

NITRATOS - Os nitratos estão presentes na água que escorre pelos troncos, em menores concentraçôes (figura 6), que as encontradas na água de chuva na Reserva Florestal Ducke (estação seca 52 ug. l-1) (Anon. 1972a).

Estes valores sugerem que, sendo o ion nitrato uma das formas de nitrogênio mais rapidamente utilizadas pela maioria das plantas quando colocadas à sua disposição, através das precipitações atmosféricas, vazando apenas pequenas quantidades para o solo, sendo também rapidamente assimiladas através do sistema radicular, fazendo com que na água do solo, esta forma de nitrogênio não se encontre mais à disposição das plantas e micropopulações que aí habitam, como mostrado por Santos \& Ribeiro (1975).

Entretanto, os valores de nitrato parecem não sofrer influências diretas das precipitações, sendo estas concentrações suficientes

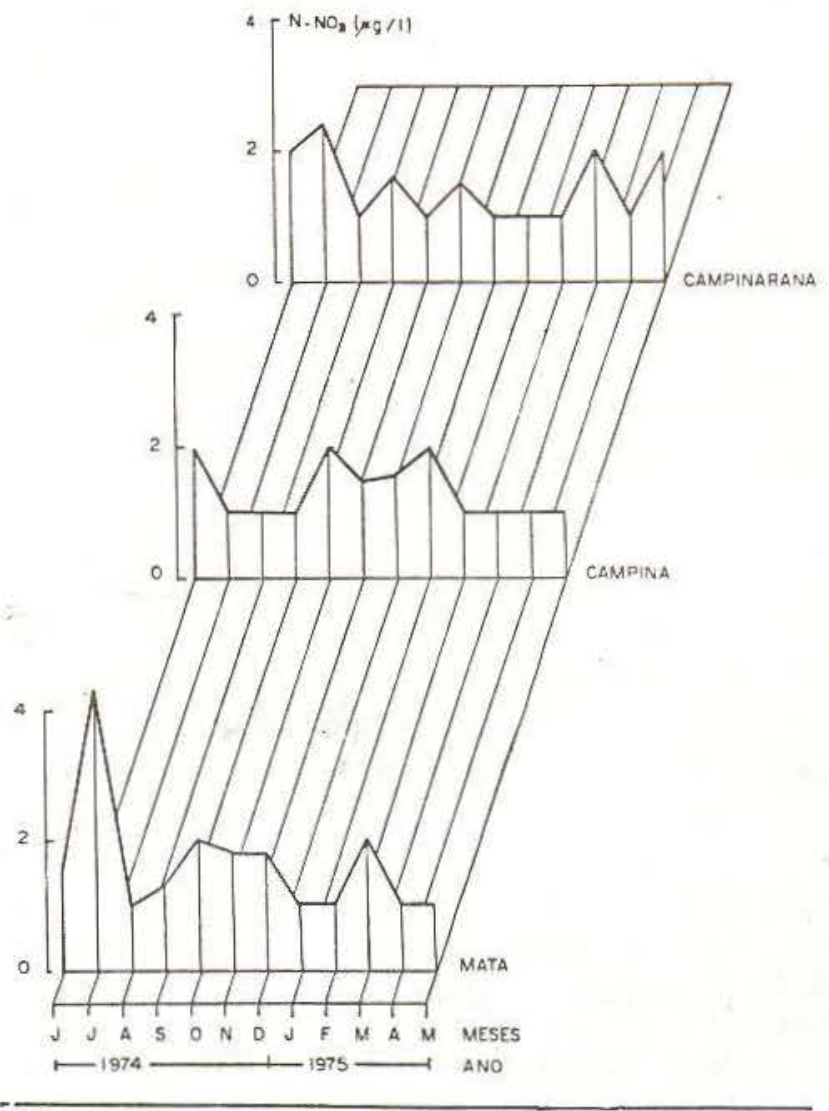

Fig. 6 - Variação sazonal de nitrogênio nítrico, mẻdias mensais. 
para permitir o abastecimento deste nutriente às populaçōes presentes nos caules das árvores da campina.

NITROGÊNIO ORGÂNICO - O nitrogênio de origem orgânica representa a maior contribuição dos compostos nitrogenados acumulados nos troncos das árvores, sendo provenientes dos restos de microorganismos produtos de excreção e ácidos aminados ligados ao complexo das substâncias húmicas, formadas e acumuladas em determinadas porções dc caule (entrecasca) da vegetação superior.

Também aqui as variaçōes sazonais são atenuadas pela distribuição das precipitações. Todavia, como é mostrado na figura 7 , existe um pico no meio do período seco ocasionado pelas chuvas de verão. Entretanto, na mata, houve um aumento acentuado na concentração de nitrogênio orgânico, no final do período seco e início do chuvoso, pressupondo uma variação qualitativa nos produtos de excreçẵo e/ou um aumento acentuado das populaçōes microbianas sobre as árvores, onde foram tomadas as amostragens.

Comparando os valores encontrados por Anon (1972a) para a água de chuva da Reserva Florestal Ducke com aqueles da figura 7 , nota-se claramente a contribuiçăo dada ao solo por esta forma de nitrogênio e a importância de serem iniciados o mais rápido possível, estudos integrados visando ao conhecimento das microbianas dentro do pálio dos ecossistemas florestais na Amazônia Central.

NITROGÊNIO TOTAL - A figura 8 mostra os valores determinados para o $\mathrm{N}$-total, isto é. o somatório de todas as frações nitrogenadas incluindo a fração albuminóide, proteínas, ácidos aminados etc., trazidos pelas precipitações e/ou excretadas pelos organismos.

Também aqui é denotada uma variação sazonal característica para $G$. inophyllum na campinarana. A presença de um pico acentuado, no meio da estação seca, é devido ao acúmulo de material lavado do dossel da floresta por chuvas isoladas neste período. O mesmo acontece para $A$. heterophylla na campina, que apresenta um pico bastante acentuado na es-

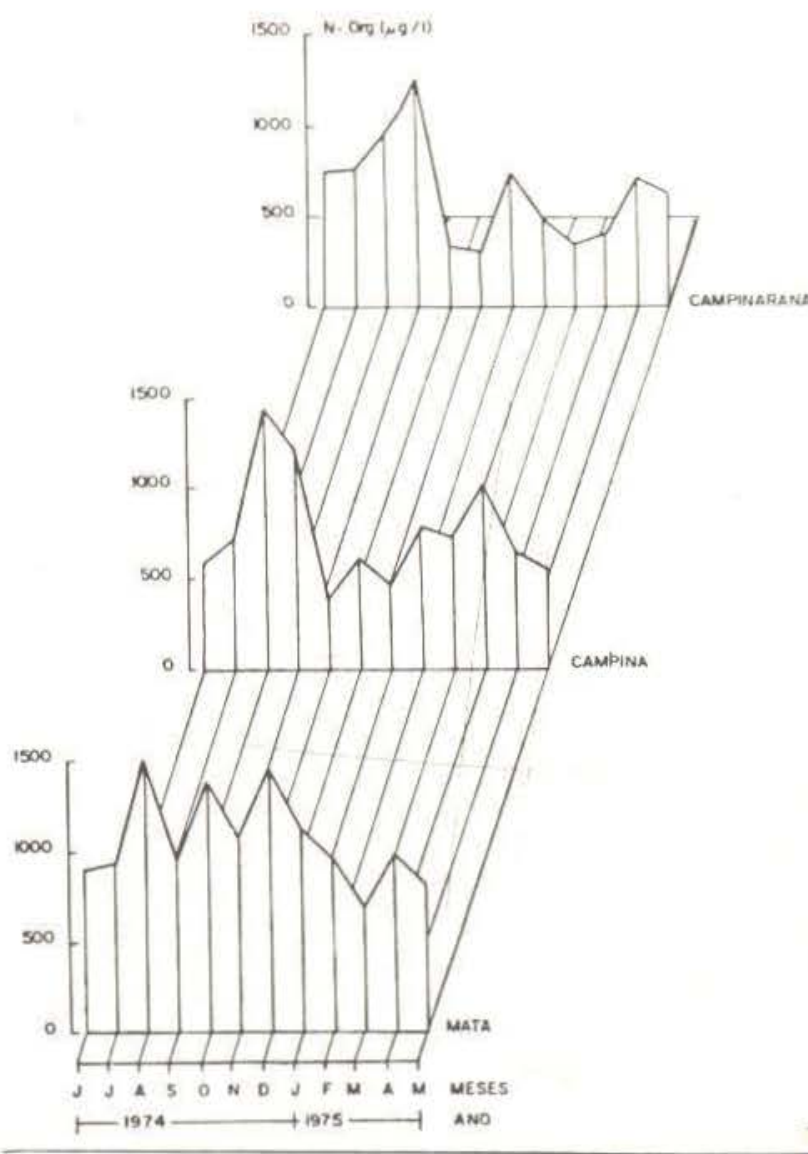

Fig. 7 - Variação sazonal de nitrogênio orgânico, médias mensais.

tação seca e outro no início da estação chuvo. sa, sugerindo que estas variaçōes sāo provocadas tanto pelas precipitações, como por atividade da fauna e flora, habitąntes desta espécie na campina. Na mata, entretanto, a concentração de nitrogênio total sofreu variaçōes acentuadas, causadas principalmente pela irregularidade das precipitaçōes, bem como pela heterogeneidade das espécies onde se instalaram os coletores, mostrando que especies diferentes apresentam variações na composição quantitativa e qualitativa de íons metabo. lizados.

FósForo TOTAL - O fósforo, presente na água dos troncos dentro do ecossistema, é todo de origem orgânica, sendo sintetizado por microorganismos e liberado como preduto de suas excreções, após a mineralização do material orgânico acumulado.

Como mostra a figura 9, na mata e campinarana, aparece uma pequena deplessão da concentração de P-total do meio até o final do 


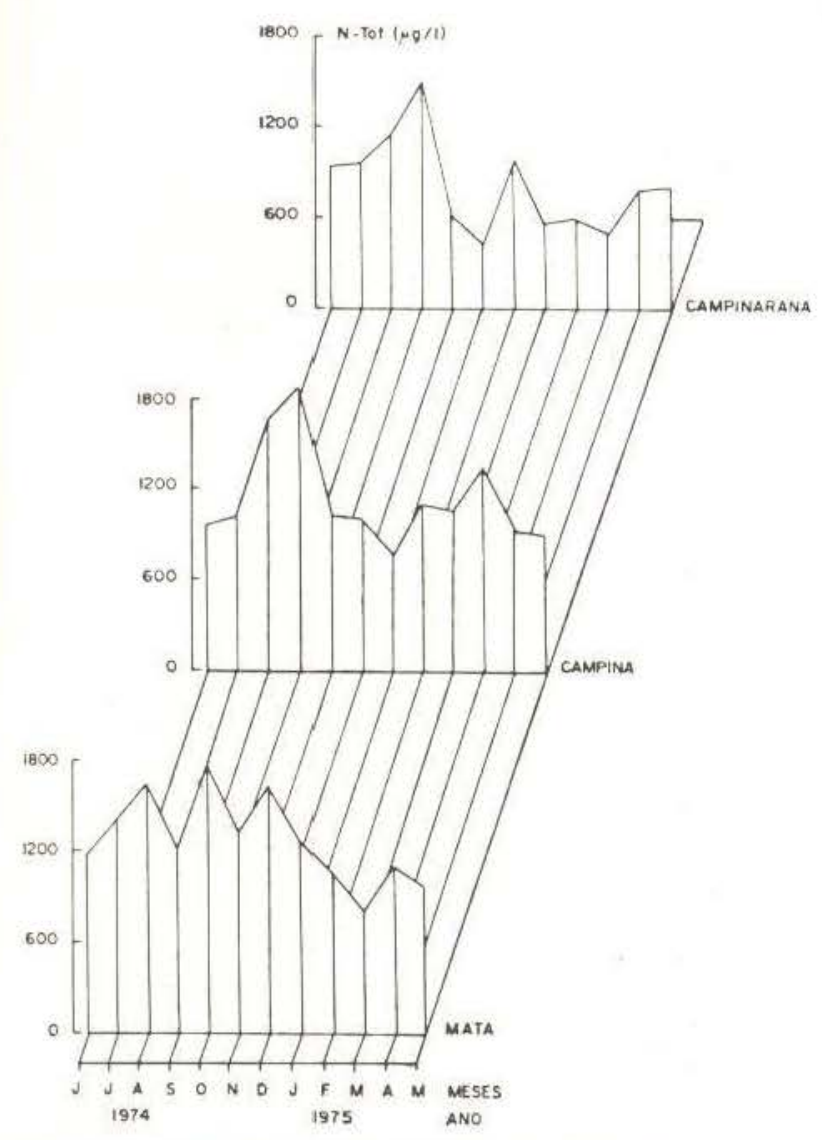

Fig. 8 - Variaçāo sazonal de nitrogênio total, médias mensais.

período chuvoso, como resultado das constantes lavagens do dossel da floresta, enquanto que, um pico é observado no meio do período seco, indicando que nesta época há acumulação de produtos metabolizados os quais são carreados para o solo com as chuvas de verão.

As quantidades de fósforo total na água dos troncos no ecossistema, estão em concordância com aqueles determinados por Anon (1972a) para água da chuva sugerem que o aporte deste nutriente para os solos das florestas, é altamente dependente da precipitação, sendo que, parte dele é utilizado pelas plantas epifíticas que se desenvolvem sobre os troncos das árvores e por estas mesmas na Reserva Biológica de Campina.

CÁlcio - O cálcio é imobilizado nas plantas principalmente nas folhas mais velhas freqüentemente na forma de oxalato de cálcio, fosfato de cálcio e em forma de sais orgâni- cos, Brinkmann \& Santos (1973). No solo, os compostos do cálcio solúveis em água estão sujeitos a constantes lavagens pelas chuvas como mostrado por Brinkmann \& Nascimento (1972)

No sistema estudado, as variações sazonais deste nutriente nos vários grupos floris. ticos, são mostrados na figura 10. Nota-se entretanto na mata, um máximo no fim do perío. do seco e na campinarana no meio deste. $\mathrm{Na}$ campina este máximo só foi alcançado no meio do período chuvoso, quando a vegetaçăo tem suas folhas mais amadurecidas.

Considerando o teor deste ín no solo arenoso da campina $(0,04-0,16 \mathrm{meq} / 100 \mathrm{~g})$. seriam necessários estudos qualitativos e quantitativos dos principais efeitos do $\mathrm{Ca}^{2}+$ nos ecossistemas florestais sobre as comunidades presentes. Comparando os valores encontrados para água dos troncos e água do lençol freático (menor que $20 \mathrm{ug} / \mathrm{l}$ ) parece confirmar-se a hipótese postulada de que este

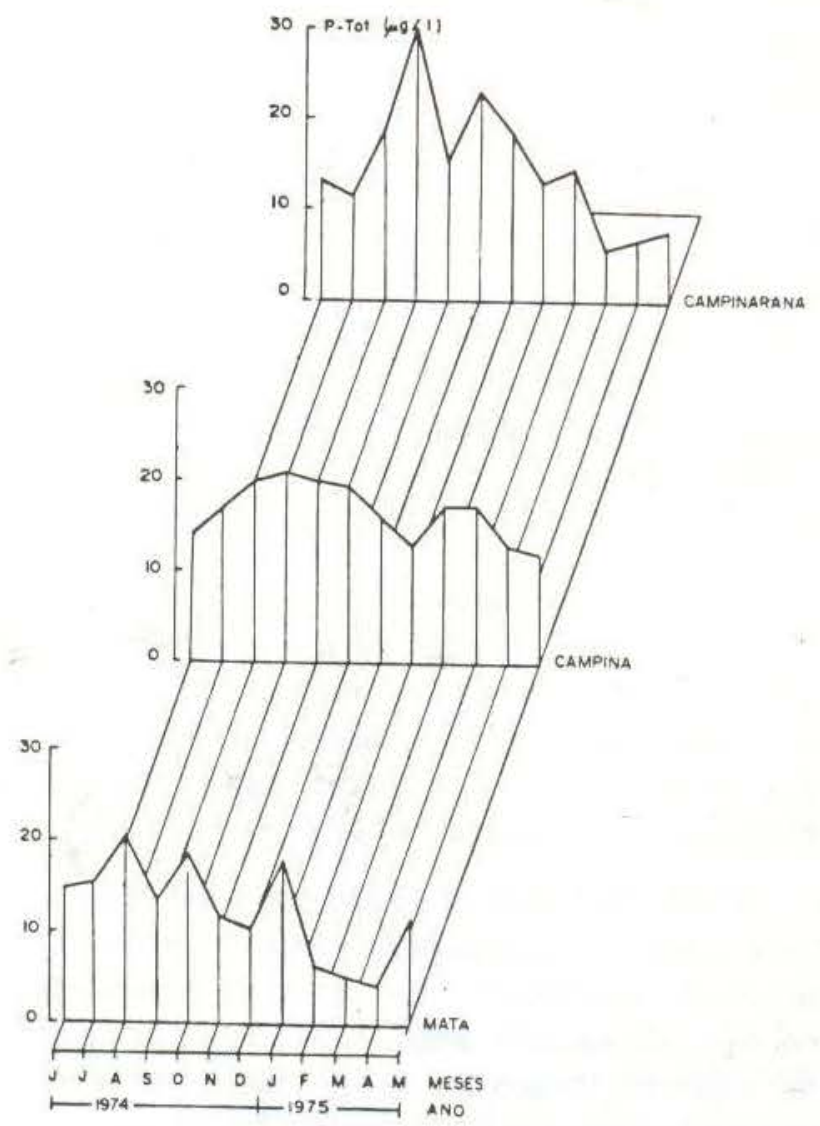

Fig. 9 - Variação sazonal de fôsforo total, médias mensais. 


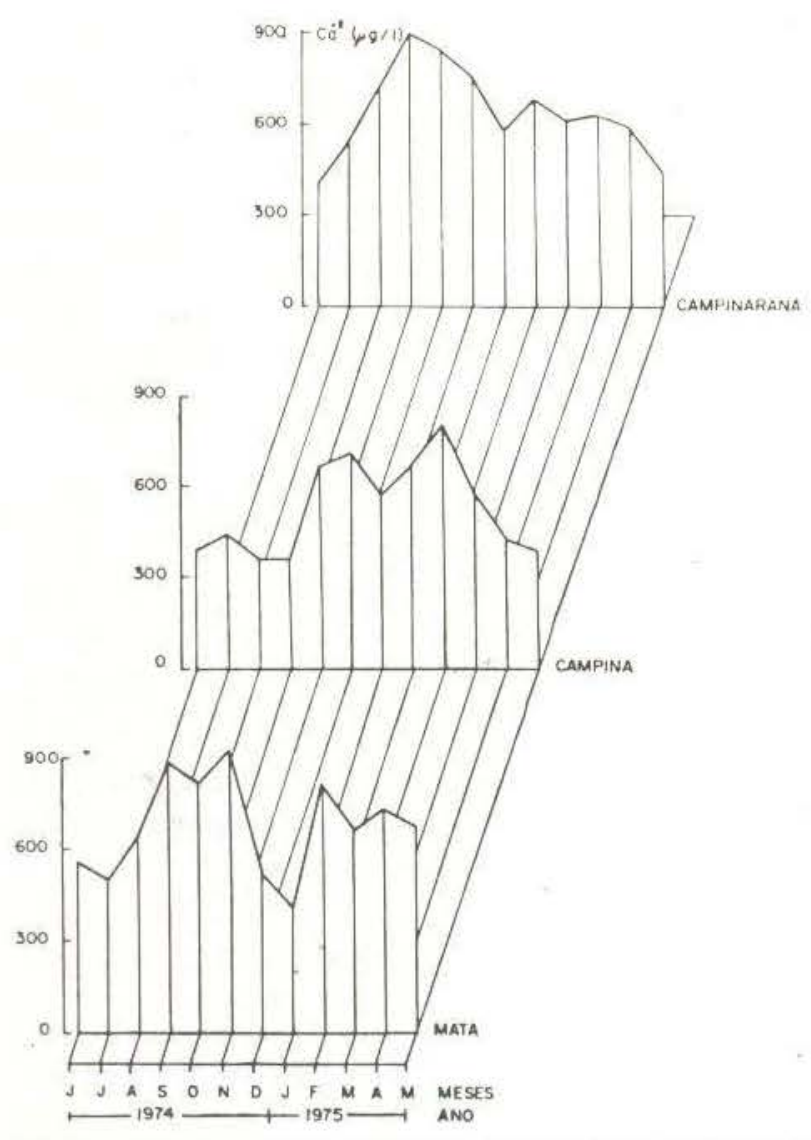

Fig. 10 - Variaçã̃o sazonal de cálcio, médias mensais.

elemento pode ser considerado como circulante num sistema fechado nos ecossistemas florestais perto de Manaus.

MAGNÉSIO - As concentrações de magnésio na água dos troncos mostram-se bastante elevadas como visto na figura 11, porém este nutriente pode ser proveniente de várias fontes. É possível que durante a oxidação da amônia nos tufos das raízes das epífitas, seja produzido ácido mineral forte como o $\mathrm{HNO}_{2}$ ou $\mathrm{HNO}_{3}$, Estes e outros ácidos orgânicos, como os fenólicos, benzenocarboxílicos e acéticos, podem então solubilizar o magnésio presente na superfície das folhas e caules.

Todavia, ocasionalmente as excreções da macro e micropopulaçōes năo fotossintetizantes podem contribuir também para as elevadas concentraçōes do magnésio na água dos troncos.

A figura 11 mostra a existência de um máximo no fim do período e outro no início do chuvoso para a mata. $\mathrm{Na}$ campina, entretanto, verifica-se um aumento gradual do fim da época seca até o meio da chuva e na campinarana as variaçōes acompanham aquelas já mencionadas para a mata.

Observa-se assim a não existência de uma variação sazonal bem definida e que as variaçōes encontradas são funçãc da distribuição irregular das precipitações, valendo ressaltar que os valores determinados para as três formaçōes florísticas no ecossistema estão, com raras exceções, bem próximos aos encontrados para dois sítios de terra na Reser. va Florestal Ducke (Brinkmann \& Santos, 1971).

\section{CONCLUSÃo}

As análises de elementos nutritivos lixiviados pela água de lavagem da floresta (stemflow) efetuadas durante um ciclo anual completo na Reserva Biológica de Campina no $\mathrm{km}$. 60 da rodovia BR-174 sugerem:

1 - Existência de flutuações sazonais nas concentrações dos elementos carreados,

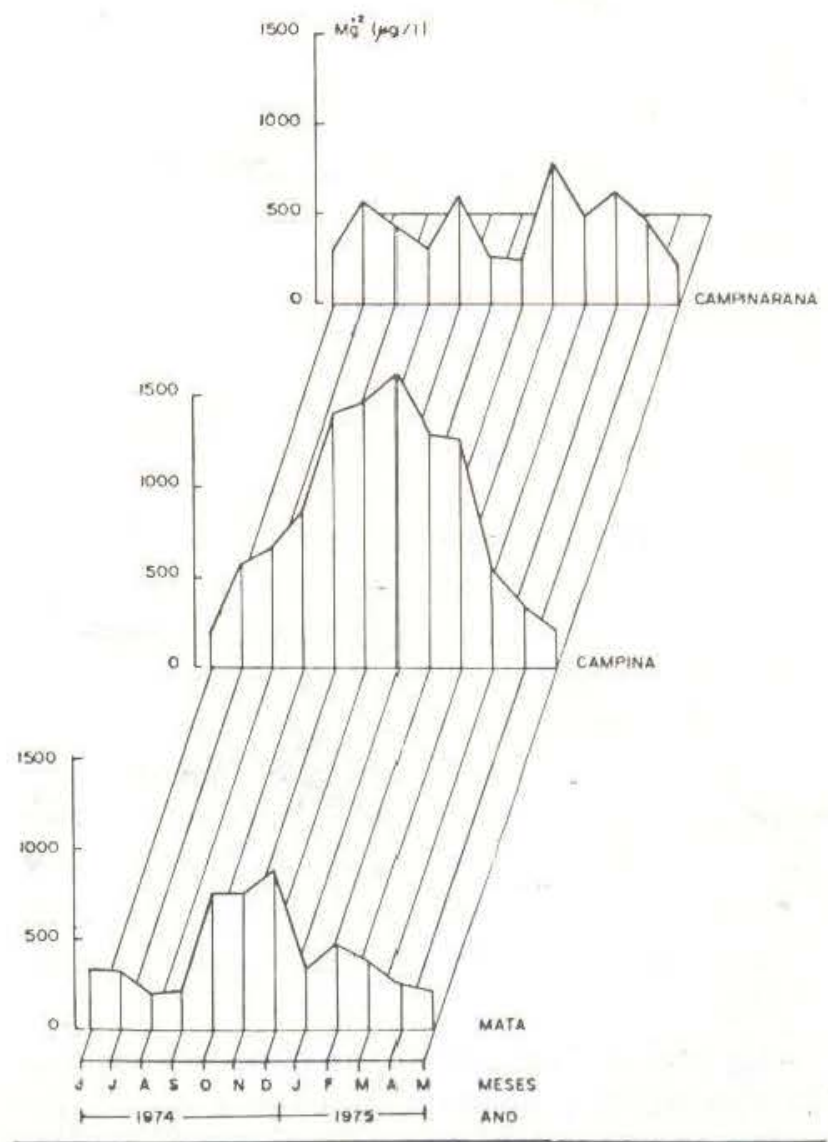

Fig. 11 - Variação sazonal de magnésio, médias mensais. 
sendo que estes dependem da intensidade, duração e distribuição das precipitações:

2 - As diferentes formaçōes floristicas contribuem com quantidades diferentes de íns, sendo que este aspecto é dependente do tipo de caule, das associações vegetais instaladas nos mesmos, da fisiologia das espécies. bem como da excreção e do metabolismo das populações microbianas eventualmente presentes nas mesmas:

3 - O nitrogênio é o principal nutriente lixiviado do dossel da floresta nas diferentes composições estudadas, quando consideradas como um todo ou em particular como mostrado a seguir.

Total lixiviado $(\mathrm{g} / \mathrm{l}): \mathrm{N}=38,2 \mathrm{Ca}=22,3$; $M g=20,8 ; P=0,53$.

Total por agrupamento $(\mathrm{g} / \mathrm{I})$ :

Mata: $\mathrm{N}=15,2 ; \mathrm{Ca}=8,2 ; \mathrm{Mg}=5,1 \mathrm{e}$ $P=0,15$.

Campina: $\mathrm{N}=13,2 ; \mathrm{Ca}=6,4 ; \mathrm{Mg}=10,3$ e $P=0,19$.

Campinarana: $\mathrm{N}=9,8 ; \mathrm{Ca}=7,7 ; \mathrm{Mg}=$ 5,3 e $P=0,18$;

4 - Entre os compostos nitrogenados, a maior excreção foi de nitrogênio orgânico nas três formaçōes florísticas. Contudo, existem diferenças: a mata contribui com $39,8 \%$, a campina com $34,6 \%$ e a campinarana com $25,7 \%$ do total;

5 - O material orgânico, entretanto, é a maior contribuição quantitativa das composições estudadas, mostrando uma entrada por meio da água de lavagem da floresta da ordem de $2,8 \mathrm{~g} / \mathrm{l}$ para a mata; $2,1 \mathrm{~g} / \mathrm{l}$ para a campina e de $1,6 \mathrm{~g} / \mathrm{l}$ para a campinarana. Entretanto, dada a natureza complexa dos compostos presentes, tornou se difícil qualificar uma fração definida através do método analítico utilizado em sua determinação, podendo, no entanto, ser acrescentado que esta fração orgânica contém como compostos básicos carboidratos, proteínas, taninos, ligninas e aminoácidos:

6 - Em vista dos resultados obtidos nesta abordagem preliminar, torna-se patente que estudos integrados de microbiologia, fenologia, botânico e físico-químico, deveriam ser conduzidos nas formações florestais equatoriais, a fim de que, se obtenham, no menor espaço de tempo, respostas concretas a cerca de reciclagem de nutrientes, das causas e das conseqüências do desmatamento, bem como a obtençāo de um banco de dados que permita por extrapolação, uma indicação mais precisa da quantidade e qualidade de nutrientes essenciais que precisam ser incorporados nos solos a serem cultivados.

Finalmente vale salientar que, o balanço entre estes parâmetros e variáveis determinam basicamente a estrutura e funcionamento de um ecossistema terrestre. Assim, com informações mais detalhadas, serão possíveis desenvolver "budgets" químicos para ecossistemas individuais e até certo ponto transferir estes dados para sistemas maiores com as mesmas características.

\section{SUMMARY}

During the period of June 1974 to May of 1975 , three floristics groups were studied in the Biological Reserve of Campina at BR-174 road.

The principle task of the research was to quantify the input of nutrient ions and organic materials, for use by macro and micro populations as sources of energy and food, by rain from the forest canopy (stemflow). The results (montiy average) showed little differences in the concentrations of total- $P$, and nitrate-nitrogen, while ammonia nitrogen, organic nitrogen and magnesium, showed different quantities of leaching in each of the three floristic groups.

The total nitrogen compounds, the most easily leached, were followed in decreasing order by calcium, magnesium and phosphorus for all system, except for Campina where magnesium ions showed greater concentrations than calcium. Total organic materials always had the greatest quantities of leaching.

Seazonal variations in leaching of the nutrient ions and organic materials from the forest to soil are closely related to the duration, intensity and distribution of rain in the study site.

\section{REFERENCIAS BIBLIOGRAFICAS}

ANDERSON, A.B.; PRANCE, G.T.; ALBUQUERQUE, B.W.P.

1975 - Estudos sobre a vegetaçăo das campinas amazônicas. III - A vegetação lenhosa da campina da Reserva Biológica, INPA-SUFRAMA (Manaus-Caracarai $\mathrm{Km}$ 62). Acta Ama. zonica, 55 (3): 225-246. 
ANON

1972a - Regenwasseranalysen aus Zentralamazonie, ausgeführt in Manaus. Amazonas, Brasilien, von $\mathrm{Dr}$. Harald Ungmaceh. Amazonian, 3 (2): $186-198$

$1972 b-$ Die Ionenfracht des rio Negro, Staat Amazonas, Brasilien, Nach untersuchung von $\mathrm{Dr}$. Harald Ungemach. Amazoniana, 3 (2): 176185.

ATTWILL, P.M.

1966 - The chemical composition of rainwater to recycling of nutrients in mature eucalyptus forest. Plant and Soil, 24: 390-406.

BORMAN, F.H. \& LIKENS, G.E.

1967 - Nutrient cycling. Science, 115: 424-429.

BRAGA, M.M.N. \& BRAGA, P.IS.

1975 - Estudos sobre a vegetaçâo das campinas amazônicas IV. Estudos ecológicos na campina da Reserva Biológica, INPA-SUFRAMA (Manaus-Caracarai $\mathrm{Km} \mathrm{62).} \mathrm{Acta} \mathrm{Amazoni-}$ ca, 5 (3): 247-260.

BRINKMANN, W.L.F. \& SANTOS, A. dos

1970 - Natural Waters in Amazonia. II - The chemical oxygen demand (COD). Symposium Proceedings on Environment in Amazonia, Part. I: $51-56$.

1971 - Natural Waters in Amazonia, V - Soluble Magnesium Properties. Turrialba, 21 (4): 459-465.

1972 - Natural Waters in Amazonia. IV - Total Iron Properties. Symposium Proceedings on Environment in Amazonia, Manaus, Part III.

1973 - Natural Waters in Amazonia VI. Soluble Calcium Properties. Acta Amazonica, 3 (2): $33-40$.

CARLISE, A.; BROWN, A.H.F.; WHITE, E.J.

1966 - The organic matter and nutrient elements in the precipitation beneath a sessible oak (Quercus patraea) cabony. J. Ecology, 54: 87-98.

GOSZ, J.R.; LIKENS, G.E.; BORMANN, F.H.

1972 - Nutrient content of litterfall on the Hubbard Brook Experimental Forest, New Hampshire. Ecology, .53: 769-784.

IPEAAOC

1971 - Solos do Distrito Agropecuário da SUFRA. MA. Série Solos, 1 (1): $100 \mathrm{p}$.

IPEAN

1969 - Os solos da área Manaus-Itacoatiara. Série Estudos e Ensaios, 1 (1): 117 p.

KIRA, T. \& SHIDEI, T.

1967 - Primary production and turnover of organic matter in different forest ecosystems of the Western Pacific. Jap. J. Ecology, 17: 70-87.
KLINGE, H.

1976a - Root mass estimation in lowland tropical rain forest of Central Amazonia, Brasil. III - Nutrientes in fine roots from Giant Humus podsols. Tropical Ecology, 16 (1): 2838.

1976b—Nährstoffe, Wasser und Durchwurzelung von Podsolen und Latosolen unter Tropishen Regenwald bei Manaus/Amazonie Biogeographica, 7: 45-58.

1977 - Preliminary data on nutrient release from decomposing leaf litter in a neotropical rain forest. Amazoniana, 6 (2): 193-202.

KLINGE, H. \& RODRIGUES, W.A.

1968 - Litter production in an area of Amazonian terra firme forest. Part I. Litter-Fall, Organic Carbon and Total Nitrogen contents of litter. Amazoniana, 1 (4): 287-302.

1971 - Matéria orgânica e nutrientes na mata de terra firme perto de Manaus. Acta Amazonica, 1 (1): 69-72.

1974 - Ptytomass estimation in a Central Amazonian Rain Forest. In: IUFRO BIOMASS STUDIES, Univ. Press, Orono, Maine: 337 350 .

LISBOA, P.L.

1975 - Estudos sobre a vegetaçāo das campinas Amazônicas. II - Observaçōes gerais e revisăo bibliográfica sobre as campinas amazônicas de areia branca. Acta Amazonica, 5 (3): $211-223$.

MECKLENBURG, R.A. \& TUCKEY, H.B.

1964 - Influence of foliar leaching on root upake and translocation of calcium- 45 to the stems and foliage of Paseolus vulgaris. PI. Physiol., Lancaster, 39: 533-536.

RIBEIRO, M.N.G.

1976 - Aspectos climatológicos de Manaus. Acta Amazonica, 6 (2): 229-233.

RIBEIRO, M.N.G. \& SANTOS, A. dos

1975 - Observaçōes microclimáticas no ecossistema Campina Amazônica. Acta Amazonica, 5 (2): $183-189$.

RIBEIRO, J.S.B.; BRINGEL, S.R.B.; SANTOS, A. dos

1978 - Hidroquimica da Amazônia Central II. Flutuações no fluxo de saída de nitrogênio $e$ fósforo em dois ecossistemas na Amazônia. Acta Amazonica, 8 (3): 409-416.

REISS, $\mathrm{F}$.

1976 - Qualitative and quantitative investigations on the macrobenthic fauna of Central Amazon lakes. I. Lago Tupé, a black water lake on the lower Rio Negro. Amazoniana, 6 (2): 203-235. 
SANTOS, A. dOS \& RIBEIRO, M.N.G.

1975 - Nitrogênio na água de solo de ecossistema Campina Amazônica. Acta Amazonica, 5 (2): 173-182

SANTOS, A. dos; BRINGEL, S.R.B.; RIBEIRO, J.S.B.

s.d. - Hidroquimica da Amazônia Central. I Perdas de elementos nutritivos no ecossistema Campina Amazônica (nâo publicado).

SCHMIDT, G.W.

1972 - Chemical properties of some waters in the tropical rain-forest region of Central-Amazonia along the new road Manaus-Caracaraí. Amazoniana, 3 (2): 199-207.

SIOLI, H.

1956 - O Rio Arapiuns. Bol. Téc. Instituto Agronômico do Norte, 32: 1-70.

STARK, N.

1971a- Nutrient Cycling 1. Soils. Tropical Ecology, 12 (1): 24-50.

$1971 b-$ Nutrient Cycling II. Vegetation. Tropical Ecology, 12 (2): 117-201.
STARK, N. \& HOLLEY, C.

1975 - Final Repport on studies of nutrients cy. cling on white and blackwater areas in Amazonia. Acta Amazonica, 5 (1): 51.76

TUCKEY, H.B.: MECKLENBURG, R.A.; MORGAN, J.V.

1965 - Loss nutrients by foliar leaching as determined by radioisotopes. Proc. Am. Soc. Hort. Science, 71: 496-506.

THOMAS, W.A.

1969 - Acumulation and cycling of calcium by doowoods trees. Ecol. Monographs, 39: 101-120.

VIEIRA, L.S.

1975 - Manual da Ciência do Solo. Editora Agronômica CERES. São Paulo. 464 p

VILLA NOVA, N.A.; SALATI, E.; MATSUI, E.

1976 - Estimativa da evapotranpiração na Bacia Amazỏnica. Acta Amazonica, 6 (2): 215-228.

WITTWER, S.H. \& TEUBNER, F.G.

1969 - Foliar absorption of mineral nutrients. Rev. PI. Physiology, 10: 13-32.

(Aceito para publicação em 19/02/81) 